\title{
PENGARUH PEMBERIAN LEAFLET DAN REMINDER TERHADAP OUTCOME TERAPI DAN KEPATUHAN PASIEN HIPERTENSI GERIATRIK DI RSUD A. WAHAB SJAHRANIE SAMARINDA
}

\author{
Rinda Aulia Utami*, Nurul Annisa, Victoria Yulita F., Adam M.Ramadhan \\ Laboratorium Penelitian dan Pengembangan FARMAKA TROPIS Fakultas Farmasi \\ Universitas Mulawarman Samarinda, Kalimantan Timur \\ *email: rindaaulia.utami@gmail.com
}

\begin{abstract}
ABSTRAK
Hipertensi merupakan salah satu masalah kesehatan masyarakat di dunia yang merupakan penyakit degeneratif yang berakibat polifarmasi. Tujuan penelitian ini adalah mengetahui pengaruh pemberian leaflet dan reminder terhadap ketercapaian outcome terapi dan kepatuhan pasien. Pemberian leaflet dan reminder merupakan salah satu upaya untuk meningkatkan efektifitas terapi dan kepatuhan pada pasien geriatrik. Penelitian ini menggunakan metode penelitian quasi experimental prospektif dengan teknik purposive sampling. Hasil penelitian menunjukkan bahwa terdapat pengaruh yang signifikan dari pemberian leaflet dan reminder pada rata-rata perbandingan tekanan darah sistol sebelum dan sesudah dengan nilai $p$ value yaitu 0,020 sedangkan pada rata-rata perbandingan tekanan darah diastol sebelum dan sesudah tidak terdapat pengaruh yang signifikan dengan nilai $p$ value yaitu 0,173 dan tidak ada pengaruh yang signifikan dari pemberian leaflet dan reminder terhadap kepatuhan responden hipertensi geriatrik dengan $p$ value yaitu 0,915. Pengontrolan gaya hidup pada pasien hipertensi geriatrik dengan pengaruh pemberian konseling tambahan dari apoteker diharapkan untuk dapat di teliti lebih lanjut.
\end{abstract}

Kata kunci: Hipertensi , Leaflet dan Reminder

\begin{abstract}
Hypertension is one of the public health problem in the world which is a degenerative disease that results polipharmacy. The purpose of this study was to determine the effect of leaflets and reminder to achievement of therapeutic outcome and patient compliance. The awarding of the leaflets and reminder is one of the efforts to improve the effectiveness of therapy and geriatric patient compliance. This research uses quasi experimental research methods a prospective sampling technique with purpusive. The results showed that there is significant influence from the provision of leaflets and a reminder to the average ratio of systolic blood pressure before and after the $p$ value is 0.020 , while the average ratio of the blood pressure of diastole before and after no significant difference with $p$ value is 0.173 and no significant effect on the provision of leaflets and a reminder to the respondent compliance geriatric hypertension with $p$ value is 0.915 . Controlling lifestyle in hypertensive patients with geriatric effect of additional counseling from pharmacists are expected to be investigated further.
\end{abstract}

Keywords : Hypertension, Leaflets and Reminder 


\section{PENDAHULUAN}

Hipertensi didefinisikan sebagai kejadian meningkatkan tekanan darah arteri secara terus menerus. Pasien dengan tekanan darah diastolik atau diastolik blood pressure (DBP) dengan nilai $<90 \mathrm{mmHg}$ dan tekanan darah sistolik atau systolic blood pressure (SBP) dengan nilai $\geq 140 \mathrm{mmHg}$ telah tergolong pasien hipertensi. Lebih dari $90 \%$ individu dengan hipertensi primer. Hipertensi primer diindikasi karena karena faktor genetik, faktor genetik terkait keseimbangan natrium, pelepasan nitrit oksida, ekskresi aldosteron, angiostensin. Kurang dari $10 \%$ pasien memiliki hipertensi sekunder, dimana terdapat penyakit penyerta atau obat menjadi penyebab meningkatnya pada tekanan darah arteri (Dipiro, et al, 2005).

Berbagai perubahan fisiologis akibat proses penuaan akan dialami oleh lansia yang diantaranya adalah penurunan kemampuan jantung yang dapat memicu terjadinya hipertensi. Bertambahnya usia membuat kesehatan menurun sedikit demi sedikit. Kadar kolesterol total akan meningkat secara bertahap seiring dengan bertambahnya usia. Berdasarkan JNC VII pada lansia dikatakan hipertensi apabila tekanan darah sistolik > $160 \mathrm{mmHg}$ dan diastolik > $100 \mathrm{mmHg}$ (Kowalski, 2007).

Hasil optimal dalam manajemen hipertensi di dukung pengaturan gaya hidup oleh pasien sendiri. Komponen manajemen diri termasuk kepatuhan sehari-hari dan kepatuhan jangka panjang untuk modifikasi gaya hidup dan farmakoterapi, serta memperhatikan pemantauan dan tindak lanjut organisasi kesehatan ditantang dengan pengembangan dan implementasi strategi biaya yang efektif untuk meningkatkan kontrol hipertensi pada populasi pasien yang besar. Menyadari bahwa pengetahuan pasien dan motivasi yang penting bagi manajemen diri, strategi untuk meningkatkan kesehatan masyarakat yang salah satunya termasuk peningkatan komponen dari pendidikan pasien yang dimiliki (Hunt, 2004).

Berbagai alat bantu pengajaran tersedia untuk digunakan dalam memberikan pendidikan kepada pasien. Pemilihan alat bantu yang tepat bergantung pada metode intruksional yang dipilih. Alat bantu pengajaran antara lain materi cetak, merupakan alat bantu pengajaran antara lain alat dengan media cetak, merupakan alat yang mengajar bentuk tulis yang tersedia seperti booklet, leaflet, dan pamflet. Materi dalam materi cetak harus dapat dibaca dengan mudah oleh peserta didik, informasi harus akurat dan aktual, metode yang digunakan harus metode yang ideal untuk memahami konsep dan hubungan yang kompleks, gambar atau foto, kedua media ini lebih disukai daripada sesungguhnya. Gambar memperlihatkan secara detail dalam objek nyata, objek fisi, penggunaan perlengkapan objek atau model yang dapat dimanipulasi dari kreatifitas atau kerajinan (Potter, 2005).

Terapi untuk menurunkan tekanan darah meliputi obat dan langkah-langkah non obat yang dikenal sebagai modifikasi gaya hidup, seperti merokok dan asupan alkohol. Kontrol tekanan darah jangka panjang memerlukan penyesuaian obat dengan mempertimbangkan kehidupan sehari-hari untuk mendukung kepatuhan pasien pasien dalam pengobatan. Salah satu strategi yang dapat memfasilitasi dukungan tersebut dengan menggunakan telpon seluler dalam proses pemberiaan perawatan kesehatan. Secara global, ponsel telepon telah menjadi alat yang sering digunakan untuk komunikasi dan akses ke informasi menyatukan komunikasi dan teknologi. Ponsel-ponsel berbasis intervensi bisa mengatasi tingkat kesehatan dan dukungan membuat pasien dan tenaga kesehatan menjadikan komunikasi lebih mudah. Pesan teks memilki potensi untuk memberikan informasi saja atas menyediakan komunikasi dua arah. Beberapa pengobatan menunjukkan bahwa pengingat melalui sistem layanan pasien pendek dengan meningkatkan kunjungan klinik, referensi dalam perawatan, dan kepatuhan minum obat (Bobrow, 2014). 


\section{METODE PENELITIAN}

\section{Rancangan Penelitian}

Penelitian merupakan studi eksperiman dengan rancangan Purposive sampling. Purposive sampling adalah teknik pengambilan sampel yang dilakukan dengan cara langsung tanpa acak dan pengambilan sampel dipilih berdasarkan karakteristik tertentu. Penelitian ini menggunakan dua kelompok, kelompok pertama diberikan leaflet dan reminder dan kelompok kedua sebagai kontrol tidak diberikan leaflet dan reminder.

\section{Populasi dan sampel}

Populasi dalam penelitian ini adalah seluruh pasien yang berusia $\geq 60$ tahun yang menderita hipertensi. Pengambilan sampel dengan cara langsung dengan teknik Porpusive sampling.

\section{Instrumen Penelitian}

Instrumen yang dipakai pada penelitian ini adalah dengan menggunakan lembar kuisoner dan diajukan dari peneliti kepada subjek peneliti.

\section{Teknik Pengumpulan Data dan Analisis Data}

Pengumpulan data dilakukan dengan pencatatan rekam medik meliputi data tekanan darah sistolik dan diastolik. Data kepatuhan dikumpulkan dan diidentifikasi dengan kuisoner Morisky Medication Adherence Scale (MMAS) 8.

Data yang sudah didapatkan kemudian didistribusikan lalu diolah secara statistik menggunakan analisis data chi-square. Teknis analisis chi-square digunakan untuk analisis pengaruh pemberian leaflet dan reminder terhadap penurunan tekanan darah dan untuk analisis pengaruh pada pemberian leaflet dan reminder terhadap kepatuhan pasien.

\section{HASIL PENELITIAN}

\section{Karakteristik Pasien Hipertensi Geriatrik di Instalansi Rawat Jalan RSUD A. Wahab Sjahranie Samarinda}

Pada penelitian pertama didapatkan hasil karakteristik pasien yaitu jenis kelamin, riwayat pendidikan, riwayat merokok, dan riwayat hipertensi. Distribusi pasien hipertensi geriatrik berdasarkan jenis kelamin didapatkan angket yang berisikan pertanyaan yang hasil bahwa perempuan 58\% mengalami hipertensi geriatrik dibandingkan laki-laki yang hanya $42 \%$. Hasil penelitian diatas telah sesuai dengan teori bahwa perempuan dengan rentang umur 55-74 tahun lebih banyak menderita hipertensi dibandingkan laki-laki, hal tersebut karena pada usia tersebut memasuki masa menopause (Wisudawan, 2013). Perubahan hormonal ketika wanita memasuki masa menopause dapat meningkatkan resiko penyakit degeneratif seperti hipertensi. Pada JNC 7 dijelaskan mengenai hasil penelitian yang berupa yaitu minimal 30 menit/hari dalam seminggu menunjukkan pengaruh menopause terhadap tekanan darah, bahwa pada wanita postmenopause tekanan darah sistolik lebih tinggi 4-5 $\mathrm{mmHg}$ dari pada wanita premenopause.

Riwayat pendidikan, pasien hipertensi terbanyak berpendidikan SMA adalah $42 \%$. Hal tersebut telah sejalan dengan penelitian Agrina dkk (2011) tingkat pendidikan dapat mempengaruhi kemampuan dan pengetahuan seseorang dalam menerapkan perilaku hidup sehat, terutama mencegah penyakit hipertensi. Semakin tinggi tingkat pendidikan maka semakin tinggi pula kemampuan seseorang, maka makin mudah menerima informasi yang diberikan sehingga banyak pula pengetahuan yang dimiliki daripada pasien yang memiliki pendidikan rendah dan dapat mempengaruhi pengaturan gaya hidup serta menunjang terapi farmakologi dalam mengontrol tekanan darah. 
Tabel 1. Karakteristik Pasien Hipertensi Geriatrik di Instalansi Rawat Jalan RSUD A. Wahab Sjahranie Samarinda

\begin{tabular}{|c|c|}
\hline Karakteristik & Jumlah (\%) \\
\hline \multicolumn{2}{|l|}{ Jenis Kelamin } \\
\hline - Laki-laki & $42 \%$ \\
\hline - Perempuan & $58 \%$ \\
\hline \multicolumn{2}{|l|}{ Riwayat Pendidikan } \\
\hline$-\quad S 1$ & $27 \%$ \\
\hline - SMA & $42 \%$ \\
\hline - SMP & $10 \%$ \\
\hline$-\quad \mathrm{SD}$ & $13 \%$ \\
\hline - $\quad \mathrm{TK}$ & $8 \%$ \\
\hline \multicolumn{2}{|l|}{ Riwayat Merokok } \\
\hline - Iya & $2 \%$ \\
\hline - Tidak & $98 \%$ \\
\hline \multicolumn{2}{|l|}{ Riwayat Hipertensi } \\
\hline $\begin{array}{l}\quad \geq 1 \text { Tahun dan ada } \\
\text { riwayat keluarga }\end{array}$ & $42 \%$ \\
\hline $\begin{array}{ll}- & \leq 1 \text { Tahun dan ada } \\
& \text { riwayat keluarga }\end{array}$ & $5 \%$ \\
\hline $\begin{array}{l}\quad \geq 1 \text { Tahun dan tidak } \\
\text { ada riwayat keluarga }\end{array}$ & $50 \%$ \\
\hline $\begin{array}{l}-\leq 1 \text { Tahun dan tidak } \\
\text { ada riwayat keluarga }\end{array}$ & $3 \%$ \\
\hline
\end{tabular}

Riwayat merokok, hasil penelitian didapatkan bahwa pasien hipertensi yang memiliki riwayat merokok sebanyak 1 orang (2\%) sedangkan yang tidak memilki riwayat merokok ada 39 orang $(98 \%)$. Hasil penelitian berbeda dengan teori, bahwa pasien hipertensi sebagan besar perokok. Hal tersebut terjadi karena subjek penelitian kebanyakan berjenis kelamin perempuan dan berusia lanjut, terutama mencegah penyakit hipertensi sedangkan perempuan di lokasi penelitian secara budaya jarang sekali ada yang merokok. Hubungan rokok dan peningkatan risiko terkena penyakit kardiovaskuler telah banyak diteliti. Selain dari waktu lainnya menjadi perokok resiko merokok juga tergantung pada jumlah rokok yang dikonsumsi dalam seharinya. Seseorang dengan lebih dari satu pak rokok sehari menjadi 2 kali lebih rentan terkena hipertensi daripada mereka yang tidak merokok (Sugiharto, 2010).

Riwayat Hipertensi. Pasien Hipertensi yang memiliki riwayat hipertensi yaitu $\geq 1$ tahun ada riwayat keluarga sebanyak 17 orang $(42 \%), \leq 1$ tahun ada riwayat keluarga sebanyak 2 orang (5\%), $\geq 1$ tahun tidak ada riwayat keluarga sebanyak 20 orang (50\%) dan $\leq 1$ tahun tidak ada riwayat keluarga sebanyak 1 orang (3\%). Dari hasil penelitian didapatkan bahwa ada banyak pasien hipertensi memiliki riwayat hipertensi lebih dari 1 tahun dengan tidak ada riwayat keluarga sebelumnya, ini menunjukkan bahwa penderita hipertensi membutuhkan waktu yang lama dalam tahap penyembuhan farmakologinya. Menurut teori menunjukkan bahwa pasien dengan riwayat keluarga memiliki resiko yang lebih tinggi menderita hipertensi. Hasil penelitian sejalan dengan penelitian Shook (2012) yang menyatakan bahwa kelompok uji yang memilki riwayat hipertensi $20 \%$ lebih tinggi terkena 
hipertensi dibandingkan kelompok uji yang tidak memiliki riwayat hipertensi. Fenotipe resiko kardiovaskuler dapat diwariskan oleh orang tua terutama ibu, faktor dari ibu seperti interaksi antara genom janin dengan lingkungan yang ditentukan oleh fisiologi dari ibu saat pertumbuhan janin (Liu, 2014). Namun dari hasil penelitian menunjukkan hasil kebanyakan pasien hipertensi tidak ada riwayat keluarga. Banyak faktor yang mempengaruhi pasien sehingga memicu terjadinya penyakit hipertensi seperti pola makan yang tidak teratur, konsumsi garam dan alkohol yang berlebihan, dan jarangnya pasien berolahraga secara teratur.

\section{Pengaruh Pemberian Leaflet dan Reminder pada Ketercapaian Outcome Terapi Responden Hipertensi Geriatrik}

Pada pengaruh pemberian Leaflet dan Reminder pada Pasien Hipertensi Geriatrik didapatkan hasil dari uji statistik analisis data paired sample t-test menggunakan SPSS ver. 23 dengan nilai $p$ value untuk perbandingan sistol sebelum dan sesudah adalah 0,020 sedangkan $p$ value untuk perbandingan diastol sebelum dan sesudah adalah 0,173. Didapatkan pengaruh yang signifikan terhadap pemberian leaflet dan reminder dari data tekanan darah sistol sebelum dan sesudah dengan nilai $p$ value yaitu 0,020 sedangkan untuk data diastol sebelum dan sesudah tidak didapatkan pengaruh yang signifikan yaitu 0,173 yang artinya nilai $p$ value $>0,05$ tidak terdapat pengaruh yang signifikan dari pemberian leaflet dan reminder pada ketercapaian outcome terapi responden hipertensi geriatrik. Data yang digunakan merupakan tekanan darah responden geriatrik sistol dan diastol sebelum dan sesudah pemberian leaflet dan reminder.

Pada penelitian ini tidak terdapat pengaruh yang signifikan pada diastol sebelum dan sesudah terhadap ketercapaian outcome terapi responden saat diberikan leaflet dan reminder. Hasil penelitian ini tidak sesuai dengan penelitian yang dilakukan (Sheny, 2015) dimana didapatkan adanya pengaruh pemberian leaflet dan reminder dalam ketercapaian outcome terapi responden. Banyak faktor yang mempengaruhi pada penelitian ini salah satunya yaitu responden yang menjadi subjek penelitian merupakan responden hipertensi dengan usia diatas 60 tahun yang tergolong responden geriatrik selain itu tidak adanya perlakuan khusus pada responden di pemeriksaan awal dan akhir tekanan darah responden. Pada responden yang berusia lanjut mengalami beberapa penurunan yaitu salah satunya adalah penurunan beberapa fungsi organ tubuh seperti menurunnya sistem imun. Kemampuan imunitas tubuh melawan infeksi menurun termasuk kecepatan respons imun dengan peningkatan usia. Hal ini menyebabkan mudahnya orang yang berusia lanjut menderita penyakit seperti kanker, penyakit kronik, infeksi dan kelainan autoimun. Selain itu terjadi perubahan anatomik pada sistem kardiovaskuler seperti jantung, pembuluh darah otak dan pembuluh darah perifer. Pada jantung terjadi penurunan elastisitas dinding aorta dengan adanya penambahan usia, disertai dengan bertambahnya kaliber aorta.

Pada penelitian ini penilaian outcome terapi di nilai dari tekanan darah sistol dan diastol. Diastol merupakan fase relaksasi atrium dan ventrikel, hal ini terjadi setelah repolarisasi berikutnya dari otot jantung sedangkan sistol merupakan fase kontraksi atrium dan ventrikel. Hal ini terjadi karena penyebaran perangsangan (eksitasi) seberang jantung. Dalam melakukan kerjanya jantung mempunyai tiga periode yaitu periode konstriksi (periode sistole), periode dilatasi (periode diastole), dan periode istirahat. Periode konstriksi (periode sistole) merupakan suatu keadaan dimana jantung bagian ventrikel dalam keadaan menguncup. Katup bikus dan trikuspidalis valvula semilinaris aourta dan valvula semilunaris arteri pulmomalis masuk ke paru-paru kiri dan kanan, sedangkan darah dari ventrikel sinistra mengalir ke aourta kemudian diedarkan ke suluruh tubuh. Periode dilatasi (periode diastole) merupakan suatu keadaan dimana jantung mengembang. Katup bikus dan trikuspidalis terbuka sehingga darah dari atrium sinistra masuk ke ventrikel sinistra dan 
darah dari atrium dekstra masuk ke ventrikel dekstra. Selanjutnya darah yang ada di paruparu kiri dan kanan melalui vena pulmonalis masuk ke atrium sinistra dan darah dari seluruh tubuh melalui vena cava masuk ke atrium dekstra. Periode istirahat yaitu waktu antara periode konstriksi (sistole) dan dilatasi (diastole) dimana jantung berhenti kira-kira 1/10 detik. Darah dapat mengatur sepanjang pembuluh darah karena adanya perbedaan tekanan darah. Mekanisme perubahan kerja jantung sehingga menghasilkan kerja yang kontinyu yaitu pada waktu sistole darah dipompa ke aourta tetapi karena ourta sebelumnya sudah berisi darah maka tambahan darah dari jantung akan tertimbun dan mengembangkan dinding aorta, kerja dinding aorta bersifat elastisitas dan pada waktu sistole darah tidak bisa regurgitas ke jantung berkat adanya klep, maka sekarang darah dapat mendorong dari elastisitas dinding aorta tersebut, dengan demikian darah mengalir secara kontinyu. Karena tenaga sistole jantung tentunya lebih besar dari tenaga elastisitas dinding aorta maka ada dua macam hasil pada pengukuran tekanan yaitu tekanan sistole dan diastole.

\section{Pengaruh Pemberian Leaflet dan Reminder Kepatuhan Responden Hipertensi Geriatrik}

Mengetahui ada atau tidak pengaruh pemberian leaflet dan reminder terhadap kepatuhan pasien dalam mengkonsumsi obat hipertensi antara kelompok pemberian leaflet dan reminder dengan kelompok yang tidak diberikan leaflet dan reminder maka digunakan data dengan uji chi-square. Penilaian kepatuhan pasien menggunakan kuisoner Morisky Medication Adherence Scale (MMAS)-8 dengan nilai skor kepatuhan tinggi (nilai 8), kepatuhan sedang (nilai $6-\leq 8$ ) dan kepatuhan rendah (nilai $\leq 6$ ). MMAS yang digunakan sudah divalidasi dan digunakan untuk pasien-pasien hipertensi (Morisky et al., 2008).

Hasil penelitian berupa analisis data statistik dengan uji chi-square didapatkan nilai $\mathrm{p}>0,05$ yang artinya tidak ada pengaruh yang signifikan terhadap kepatuhan pasien pada kelompok yang diberikan leaflet dan reminder dan yang tidak diberikan leaflet dan reminder pada pasien hipertensi. Nilai $p$ value yang didapatkan yaitu 0,915 artinya tidak terdapat pengaruh yang signifikan terhadap kepatuhan pasien. Pemberian leaflet dan reminder diharapkan dapat mempengaruhi perilaku pasien dalam rutin dalam mengkonsumsi obat sehingga dapat dilihat pengaruhnya. Perilaku pasien (behaviours of patients) adalah aksi atau reaksi yang dilakukan pasien terhadap suatu hal secara sadar atau tidak sadar maupun sukarela atau terpaksa. Trans Theoretical Model (TTM) dikembangkan oleh Prochaska dan Diclemente pada tahun 1980-an. TTM adalah ilmu yang mempelajari tentang perubahan tahapan perilaku pasien (Taylor,2006). Menurut hasil yang didapatkan pasien dikategorikan dalam tingkat kepatuhan pasien tinggi, rendah dan sedang dalam tabel hasil penelitian untuk pasien yang berada dalam kategori sedang dimasukkan dalam kategori tinggi.

Pada penelitian ini kepatuhan yang dikategorikan rendah disebabkan karena responden yang lupa dalam mengonsumsi obat secara teratur, serta tingkat kejenuhan responden dalam mengkonsumsi obat dan mengurangi atau berhenti minum obat hipertensi tanpa memberitahu dokter karena merasa kondisi memburuk. Beberapa faktor yang mempengaruhi perilaku responden dalam tingkat kepatuhan yaitu aktivitas responden yang begitu banyak, keluarga yang terkadang acuh dalam mengingatkan responden mengkonsumsi obat secara teratur. Pada kepatuhan responden ada banyak faktor yaitu perilaku responden dalam diri sendiri yang memunculkan untuk tidak ingin mengkonsumsi obat secara teratur. cukup mempengaruhi dalam ketercapaian outcome terapi responden dan kepatuhan responden hipertensi usia untuk itu memerlukan peranan lebih dari tenaga kesehatan farmasis. Banyak faktor yang mempengaruhi kepatuhan dalam diri responden yaitu diantara lain faktor pasien, kondisi atau keadaan, terapi, pelayanan kesehatan dan sosial ekonomi dari semua faktor - factor tersebut, faktor pasien adalah yang paling besar pengaruhnya. Menurut Brunner dan Suddart, faktor kepatuhan pasien terdiri dari variabel 
demografi seperti, usia, jenis kelamin, status sosial dan ekonomi serta pendidikan, variabel penyakit seperti kepatuhan penyakit dan hilangnya gejala akibat terapi. Variabel program teraupetik seperti komplektifitas program dan efek samping yang tidak menyenangkan dan variabel psikososial seperti intelegensia, sikap terhadap tenaga kesehatan, penerimaan, atau penyangkalan terhadap penyakit, keyakinan agama atau budaya, biaya finansial dan lainnya. Sedangkan menurut WHO faktor-faktor yang mempengaruhi kepatuhan yaitu faktor sosial atau ekonomi, faktor kondisi yang berhubungan dengan kesehatan, faktor terapi terkait dengan pasien, faktor perilaku pasien dan faktor pada sistem kesehatan. Selain itu beberapa faktor yang mempengaruhi terjadinya hipertensi seperti pola hidup dan lingkungan sehingga perlu adanya pemahaman pasien terhadap penyakit hipertensi melalui tenaga kesehatan farmasis dan adanya gerakan pharmaucetical care dalam dunia farmasi yang bertujuan untuk memaksimalkan pengobatan dan meningkatkan kualitas hidup pasien, sehingga perlu adanya penjagaan yang lebih intensif dalam meningkatkan kepatuhan pasien. dalam meminum obat dan dapat menghasilkan efek terapi yang maksimal dalam meningkatkan kepatuhan pasien.

Tabel 2 Distribusi Pengaruh Pemberian Leaflet dan Reminder pada Ketercapaian Outcome Terapi Responden Hipertensi Geriatrik

\begin{tabular}{|c|c|c|c|c|}
\hline \multirow[b]{2}{*}{ Kelompok } & \multicolumn{2}{|c|}{ Tekanan Darah } & \multirow[b]{2}{*}{$\begin{array}{c}p \text { Value } \\
\text { sistol* }\end{array}$} & \multirow[b]{2}{*}{$\begin{array}{l}p \text { Value } \\
\text { diastol* }\end{array}$} \\
\hline & $\begin{array}{l}\text { Sebelum } \\
(\mathrm{mmHg})\end{array}$ & $\begin{array}{l}\text { Sesudah } \\
\text { (mmHg) }\end{array}$ & & \\
\hline $\begin{array}{l}\text { Perlakuan } \\
\text { (Pemberian Leaflet } \\
\text { dan reminder) }\end{array}$ & $136,5 / 88$ & $129 / 83,5$ & \multirow[b]{2}{*}{.020} & \multirow[b]{2}{*}{.173} \\
\hline $\begin{array}{l}\text { Tanpa Perlakuan } \\
\text { (Tanpa pemberian } \\
\text { Leaflet dan reminder) }\end{array}$ & $149,5 / 89,5$ & $139,5 / 87$ & & \\
\hline
\end{tabular}

*Analisis menggunakan uji paired sample t-test dengan SPSS ver 23

*Perbandingan sesudah dan sebelum

Tabel 3 Distribusi Pengaruh Pemberian Leaflet dan Reminder terhadap Kepatuhan Responden Hipertensi Geriatrik

\begin{tabular}{|c|c|c|c|c|c|}
\hline & \multicolumn{3}{|c|}{ Hasil ( Kepatuhan) } & \multirow{2}{*}{ Total } & \multirow{2}{*}{$p$ Value } \\
\hline & Tinggi & Sedang & Rendah & & \\
\hline \multicolumn{6}{|l|}{ Kelompok: } \\
\hline $\begin{array}{l}\text { Perlakuan (Pemberian leaflet } \\
\text { dan reminder) }\end{array}$ & 8 & 4 & 8 & 20 & \multirow[b]{2}{*}{.915} \\
\hline $\begin{array}{l}\text { Tanpa perlakuan (Tanpa } \\
\text { pemberian leaflet } \\
\text { reminder) }\end{array}$ & 8 & 5 & 7 & 20 & \\
\hline Total & 16 & 9 & 15 & 40 & \\
\hline
\end{tabular}

*Analisis menggunakan uji chi-square dengan SPSS ver 23 


\section{KESIMPULAN DAN SARAN}

Dari penelitian ini dapat disimpulkan bahwa, didapatkan pengaruh pemberian leaflet dan reminder terhadap penurunan tekanan darah dengan analisis data chi-square didapatkan hasil yaitu terdapat pengaruh yang signifikan dari pemberian leaflet dan reminder pada ratarata perbandingan tekanan darah sistol sebelum dan sesudah dengan nilai $p$ value yaitu 0,020 sedangkan pada rata-rata perbandingan tekanan darah diastol sebelum dan sesudah tidak terdapat pengaruh yang signifikan dengan nilai $p$ value yaitu 0,173 dan untuk kepatuhan responden hipertensi geriatrik didapatkan hasil yaitu tidak ada pengaruh yang signifikan dari pemberian leaflet dan reminder terhadap kepatuhan responden hipertensi geriatrik dengan $p$ value yaitu 0,915 . Hasil dari penelitian menunjukkan bahwa pemberian leaflet dan reminder tidak cukup memberikan dampak yang signifikan terhadap tahap peningkatan pada pasien hipertensi geriatrik dengan penambahan perlakuan konseling yang lebih intensif khususnya pada pasien hipertensi geriatrik dengan faktor resiko diharapkan untuk dapat diteliti lebih lanjut.

\section{DAFTAR PUSTAKA}

Bobrow, Kirsty, Thomas Brennan, David Springer, Naomis Levitt, Brian Rayner ,Mosedi Namane, Lymee Yu, Lionel Tarassenko and Andrew Farmer. Officacy of aText Messaging (SMS) based Interventation for Adult with Hypertention; Protocol for theStar (SMS Text- Message Adherence Support Trial) Randomised Controlled Trial .BMC Public Health. 14. (28). 1471-2458

Dipiro J.T , Robert L.T. Gary C.Y, Garry R.M, Barbara G.w Michael P . 2005. Pharmacothrraphy;A Pathophysiologic Approach Sixth Edition. MC GRAW-HILL Medical Publishing Division : Unites State Of American

Hunt, J.S , and Nicola Payne. 2004. Impact Of Education Mailing On The Blood Pressure Of Primary Care Patient with Mild Hypertention. J Gen Intern Med. 19 (9) . 925930

Potter, P. A, Perry, A.G.2009. Fundamental Keperawatan. Buku Edisi 7. Alih Bahasa : Adrina Ferderika.Salemba Medika : Jakarta

Stanley., M, \& Beare, P. G. 2007. Buku Ajar Keperawatan Gerontik. Edisi 2. EGC: Jakarta 